\title{
La autonomía personal y la perspectiva comunitarista $^{1}$
}

\author{
SILVINA ÁLVAREZ \\ Universidad Autónoma de Madrid
}

El presente artículo analiza el planteamiento que algunos autores comunitaristas han hecho de la noción de autonomia personal. En primer Iugar centraré la atención en la formulación kantiana de la autonomía y en las posteriores reformulaciones que se han hecho de la propuesta original. En la scgunda parte expondré algunos aspectos generales de
Ia teoría comunitarista para luego desarrollar la propuesta de Charles Taylor, específicamente la ética de la autenticidad. En el análisis se destacan los problemas que surgen de entender la autonomía desde la perspectiva de una ética comprehensiva que concibe al sujeto como continuador de una tradición moral colectiva.

"Autonomy does not include the right to impose upon oneself, for no good reason, great harm. We ought to prevent anyone from doing to his future self what it would be wrong to do to other peoples (Derek Parfit).

\section{EL CONCEPTO DE AUTONOMÍA}

\subsection{La concepción kantiana}

El liberalismo ha encontrado en la autonomía uno de los conceptos fundamentales para su desarrollo teórico. Desde Kant la autonomía personal tiene al menos dos sentidos que la definen. Por una parte implica independencia respecto de factores externos a la voluntad de la persona. Este aspecto de la autonomía refuerza la idea de libre elección en la configuración del plan de vida individual. Por otra parte, csa capacidad de elección no puede ser ejercida sino a través de la razón. La persona autónoma se autodetermina racionalmente a través de su capacidad práctica ${ }^{2}$. La racionalidad enriquece

' La mayor parte de este trabajo fue escrita durante una estancia de investigación realizada cn la Universidad de Oxford. Agradezco al profesor Joseph Raz su ayuda y hospitalidad, y el tiempo que me dedicara para discutir algunas de mis dudas. A Albert Calsamiglia, con quien coincidi durante la estancia en Oxford, le debo el haber compartido conmigo yarias sesiones de discusión y una lista de comentarios y sugerencias, así como la generosidad y calidez de su compañía. Agradezco también a Francisco Laporta, Ernesto Garzôn Valdés y José Luis Colomer, por sus valiosos comentarios.

? Véase Colomer (1995: 32). 
la acción en varios aspectos. En primer lugar, cuando una persona conduce su vida a través de una sucesión de actos racionales, será fácil dar coherencia al conjunto de sus actos o, lo que es lo mismo, al plan de vida o trayectoria vital que de ellos se desprenda. De este modo se comprenderá mejor el sentido de las decisiones adoptadas, ubicándolas en un contexto más amplio de conducta. En segundo lugar, la persona que actúa evaluando racionalmente sus decisiones tiene la posibilidad de analizar críticamente los diversos cursos de acción posibles. Vale decir que sus elecciones contarán con un filtro importante que le permitirá discernir entre los incentivos externos que se le presenten, sea que se trate de consejos, invitaciones o estímulos en general ${ }^{3}$. El agente racional asi provisto contará entonces con la razón como tamiz de sus decisiones, lo cual le otorga una especial confianza en la calidad de sus propias elecciones. Se trata de la habilidad para hacer deducciones e inferencias, para localizar Ios puntos de conflicto frente a una situación dada y para evaluar el carácter de verdad o falsedad de una premisa ${ }^{4}$. Esta postura crítica del individuo autónomo se contrapone a la irreflexibilidad, a la toma de decisiones arbitrarias y también a la sumisión a una voluntad ajena ${ }^{5}$, es decir que se contrapone a la conducta típica de un obrar heterónomo, en el que las decisiones son tomadas bien por agentes distintos del sujeto, bien por el impulso - o condicionamiento - proveniente del contexto social que rodea a la persona.

Aunque la obra de Kant ha sido fuente de muy diversas interpretaciones y aunque la idea de libertad puede ser analizada en Kant rastreando muy diversos significados ${ }^{6}$, destacaré dos de los significados analizados por Henry Allison: el de libertad como autenticidad y el de libertad como autonomía. Respecto del primero, éste queda expresado en lo que Allison llama la «tesis de la incorporación», según la cual un incentivo puede condicionar la voluntad sólo si previamente el individuo ha incorporado ese incentivo como máxima de acción. De este modo pueden los incentivos condicionar la voluntad, que sin embargo sigue siendo libre -en el sentido de espontánea-. Las máximas

Véase Young (1986: 12).

${ }^{4}$ Véase Young (1986: 10),

" Se puede objetar en este punto que el agente racional muchas veces se somete a la voluntad de otros, como es el caso de la sumisión a la autoridad. Sobre esto Raz ha hecho notar, a propósito de una réplica al anarquismo, que un modo inteligente de ejercer la autonomía es aceptando que para ciertas cuestiones es mejor atenerse a la autoridad de otro (1994: 344). La autoridad puede basarse, por ejemplo, en el conocimiento o la pericia. Así, cuando aceptamos ir al médico y tornar la medicina que nos receta o someternos al tratamiento que nos aconseja, lo hacemos con el conocimiento de que no sólo es mejor proceder de ese modo que depender enteramente de nuestros nulos conocimientos en medicina, sino que estamos aceptando que resulta más económico para cl cjercicio de nuestra autonomía el delegar cuestiones específicas en expertos (ponernos a estudiar medicina cuando estamos enfermos, o arquitectura cuando deseamos tener una casa no sólo resultaría perjudicial para nucstros propios interescs, sino que destruiría las posibilidades de realizar las que realmente son nuestras opciones más valiosas).

' Siguiendo a Lewis White Beck señala Allison cinco concepciones de libertad en Kant: libertad empírica, libertad moral o autonomía, espontaneidad, libertad trascendental y libertad postulada (1996: 129). 
son principios subjetivos que el agente se autoimpone, y es por ello que se autodetermina al actuar conforme a ellas, al actuar espontáneamente. En algunos trabajos Kant se refiere a esta idea sobre la necesidad de incorporar los incentivos a máximas como el «complemento de suficiencia», vale decir como aquello que el agente racional debe proveer para que los incentivos no induzcan a la acción sin más. También puede leerse en la tesis de la incorporación un rechazo al determinismo causal; el agente racional es capaz de autodeterminarse con independencia de la «causalidad de la naturaleza»?

La segunda acepción de libertad utilizada por Kant que aquí nos interesa es la de libertad como autonomía. En este sentido la autonomía como principio moral no puede dejar de reconocer el imperativo categórico como una condición necesaria para su realización, ya que es a través de éste como se concreta la capacidad de auto-legislación del individuo libre. El deber ser se traduce así en un obrar que no es un medio para el logro de un fín, sino que se impone por sí mismo y por ello es categórico. Es ajeno a las condiciones subjetivas y su validez universal depende de los dictados de la razón pura ${ }^{8}$. En tal sentido, la autonomía es la capacidad del individuo para darse sus propias leyes y apartarse en consecuencia de la heteronomía. La moralidad está inseparablemente vinculada a este aspecto de la libertad, vale decir a la libertad como autonomía - no a la libertad como espontaneidad-, ya que ésta es la condición necesaria del obrar conforme a deber ${ }^{9}$.

En la mayoría de los casos el agente racional actúa realizando operaciones cotidianas de cálculo simple mediante las cuales fija sus objetivos, evalúa las opciones a su alcance para lograrlos y se decide por la opción que mejor los satisfaga. Esto no significa que en todos los casos se trate de un cálculo utilitarista o maximizador, sino que la elección puede ir acompanada de valores muy diversos que, sin desplazar la racionalidad, orientan la elección y la decisión racionales. Al plantear que el individuo autónomo se inclina por la opción que más le convenga se abren una serie de posibilidades interpretativas. Lo que más convenga al agente puede ser, en términos generales, lo que más se adecue a sus propios fines. Esto, a su vez, sigue presentando problemas. Para el utilitarismo los fines son equivalentes a los intereses, sean éstos individuales o generales, y el objetivo es maximizar esos intereses para incrementar el bienestar general. Para el comunitarismo podríamos pensar, a grandes rasgos, que los fines personales se verán satisfechos más íntegramente en la medida en que concucrden con los valores que orientan la comunidad en que el individuo desarrolla su plan de vida. Según Kant y parte del pensamiento liberal ${ }^{10}$, sin embargo, cualquier conducta orientada exclusivamente por o hacia fines es

\footnotetext{
Véase Allison (1996: 131-132).

Sobre este tema y sobre las interpretaciones del principio de universalización como criterio moral véase Colomer (1991: 49-72).

$\checkmark$ Vease Allison (1996: 138).

" Me refiero a parte del pensamiento liberal con la intención de dejar fuera algunas de las variantes consecuencialistas que podrían no obstante calificarse de liberales atendiendo a aspec-
} 
una acción instrumental que el agente racional debe someter a revisión. Las acciones basadas en motivaciones o incentivos ajenos a la razón no restan autonomía al obrar del agente siempre y cuando cumplan el requisito de universalizabilidad impuesto por el imperativo categórico. Dado que el agente valora la autonomía como capacidad para obrar racionalmente, lo que conviene al individuo no puede ser distinto de lo que conviene racionalmente, vale decir del pensar y actuar autónomamente. La autonomía es valiosa en sí misma. Lo importante para la concepción kantiana no es aquello que logramos a través del ejercicio de la autonomía, sino el ejercicio mismo que hacemos de nuestra capacidad para actuar racionalmente; no importan los resultados ni los fines que están fucra del agente autor de la conducta autónoma, no importa la idea del bien que pueda perseguirse con la acción, sino la acción misma como capacidad para elegir y optar. Es por cllo que cl deontologismo kantiano lleva consigo la idea de que la persona es anterior a sus fines y los derechos anteriores a cualquier idea del bien.

Pero tampoco debemos encasillar la autonomía bajo el imperativo de capacidad de evaluación. En muchas ocasiones una condición para ser autónomo es simplemente, en palabras de Robert Young, la de no comportarse de un modo seriamente irracional (1986: 12). Esta definición negativa de autonomía complementa la positiva - en términos de evaluación-elección-planificacióny abre un amplio campo en el que la autonomía provee, como veíamos más arriba, de coherencia y capacidad crítica. No comportarse de un modo seriamente irracional puede ser equivalente a comportarse de un modo mínimamente racional. Ambas propuestas, sin embargo, pecan de confusión y parece haber en ellas cierta falacia insalvable, ya que la razón no es una propiedad que pueda medirse o graduarse; se actúa de modo racional o, en su defecto, cualquier otro curso de acción que no se ajuste a las premisas de la racionalidad es irracional. De manera que la afirmación de Young en el sentido de que la persona autónoma debe no comportarse de un modo seriamente irracional tenemos que interpretarla en el sentido de que no siempre es necesaria una evaluación o reflexión exhaustiva para comportarse racionalmente. Una acción $x$ puede responder a mecanismos cuasi-instintivos o ser fruto de un impulso, o puede tratarse de una acción que llevamos a cabo «mecánicamente» y reunir, sin embargo, las condiciones del obrar autónomo, pudiendo ser reconstruida conforme a las premisas de racionalidad e independencia. En tal sentido nos encontraríamos frente a un obrar no ya no seriamente imacional, sino frente a una acción espontánea — cn los términos explicados más arriba- que satisface las condiciones de racionalidad en tanto se adecua a las máximas que incorporan incentivos. De tal modo puede justificarse como autónoma una acción que en apariencia sólo es producto de un impulso o intuición ${ }^{11}$.

tos diversos - como la centralidad y primacía del individuo, el respeto a la libertad personal, etcétera.

"Sobre los distintos sentidos en que puede hablarse de sirracionalidad" en el marco de los deseos como razones para actuar véase Bayón (1991: 79 a 85). 
Resumiendo, la autonomía se ve satisfecha cuando se cumplen las condiciones de racionalidad e independencia. La autonomía es en este sentido una capacidad universal, vale decir susceptible de ser adquirida por cualquicr individuo que pueda reunir las condiciones señaladas. Un niño, por ejemplo, no nace autónomo dado que su racionalidad es limitada; no puede hacer uso autónomo de su racionalidad, que deberá desarrollar con el aprendizajc, la experiencia y los desafíos a que lo enfrente el ambiente en que se desarrolle y crezca. Pero una vez alcanzada la racionalidad y la independencia, la autonomía debe ser entendida como una capacidad universal que, independientemente de las condiciones en que se haya adquirido, una vez adquirida y en tanto capacidad de la persona, es universal. La racionalidad es la misma sin importar cuál sea el contexto en que se haya adquirido. La racionalidad y la autonomía kantiana son en este sentido universales.

\subsection{El modemo concepto de autonomía}

La concepción kantiana, sin embargo, ha sido revisada y reformulada. Las reelaboraciones efectuadas muestran la complejidad del concepto de autonomía, descubriendo en ella nuevas condiciones y elementos. Algunas de las revisiones hechas en este sentido proponen que la racionalidad y la independencia no bastan para definir al individuo autónomo, sino que hacen falta conceptualizaciones que den cuenta de una variada y rica gama de posibilidades que intervienen también en la conformación de la persona autónoma y que no se reflejan en las condiciones kantianas, algunas de las cuales no se refieren a la autonomía como principio universal, sino que ponen el acento en el contexto en el que la autonomía se desarrolla y se ejerce.

En tanto condición necesaria para la autonomía, la distinción entre libertad positiva y libertad negativa ha sido de utilidad para distinguir dos importantes aspectos de la racionalidad práctica. Como es sabido, la primera hace referencia a la pasibilidad de actuar racionalmente conforme a mis fines o, más ampliamente, a mi plan de vida, mientras que la segunda se ve satisfecha con la no interferencia externa ${ }^{12}$.

Sobrc la base de esta ya clásica tipificación han surgido nuevas elaboraciones conceptuales, como, por ejemplo, la de Richard Fallon, que distingue entre el concepto descriptivo de autonomía y cl atributivo o adscriptivo (1994: 876). La autonomía descriptiva se refiere a una situación empírica en la que la autonomía es variable y depende de la medida en que cada uno se autogobierna en un universo de relaciones causales. Para que se verifique la libertad on sentido descriptivo deben reunirse ciertas condiciones: deliberación racional, conformación de una idea del bien, coherencia en el logro de los objetivos

${ }^{12}$ Sobre el concepto de libertad positiva y libertad negativa véase Isaiah Berlin, 1986, capitulo III, «Two concepts of liberty», pp. 118 y ss. 
fijados (1994: 877). Por su parte, la autonomía atributiva remite a la capacidad para tomar las propias decisiones. Presupone la idea de dignidad de la persona en tanto persona moral, así como la de soberanía personal en el sentido de ausencia de determinación. Tanto de la autonomía descriptiva como de la atributiva se puede predicar libertad negativa y libertad positiva.

La autonomía descriptiva, tal como se acaba de caracterizar, se aparta considerablemente del concepto kantiano - descrito en el apartado anteriorPara Kant condiciones como la existencia de opciones diversas o la coherencia con el plan de vida no estaban en consideración. Sin embargo, estas y otras condiciones ajenas al concepto kantiano son consideradas por muchos autores como necesarias para la realización de la autonomía.

Fallon se inclina por una definición descriptiva de autonomía resumida en su «propuesta sintética de autonomia descriptiva». Los elementos que enuncia nos servirán para analizar algunas de las condiciones que más comúnmente se mencionan al estudiar la autonomía no ya en sentido kantiano, sino en un sentido más amplio y directamente conectado con el contexto en que se desarrolla. El autor menciona las siguientes condiciones: i) actitud crítica y autocrítica; ii) ser competente para actuar en el mundo, iii) existencia de opciones suficientes, y iv) ausencia de coerción y manipulación (1994: 886). La condición i) se refiere a la capacidad para reflexionar sobre las razones para la acción -gustos, deseos, preferencias, objetivos, etc.-. Esta capacidad para la reflexión se contrapone a los simples impulsos o emociones como móviles para la acción - salvo que estuvieran mediados por máximas (tesis de la incorporación) - . La condición ii) hace referencia a la aptitud física y mental del individuo, así como al dominio sobre su propia persona (por ejemplo, alguien que hiciere un uso continuado de sustancias estupefacientes podría llegar a perder la capacidad de decidir libremente sobre su vida) ${ }^{1.3}$. El requisito de las opciones suficientes iii) se refiere a las oportunidades para la elección, y autores como Joseph Raz han señalado su importancia decisiva para el ejercicio de la autonomía. Los siguientes párrafos estarán dedicados al análisis de este punto.

Para que pueda hablarse de elección el agente debe tener ante sí una gama de posibilidades que dé cuenta de una diversidad no meramente cuantitativa, sino cualitativa. Es el clásico caso del esclavo cuyas opciones están limitadas por la autoridad del amo, lo cual impide hablar de verdadera capacidad de elección por parte de aquél, aun cuando pueda optar entre una serie de alternativas. La simple existencia de una gran variedad de opciones no garantiza que el agente pueda escoger entre las opciones verdaderamente relevantes.

${ }^{3}$ Cabe hacer aquí una mención metodológica respecto del orden en que Falton presenta las condiciones; parecería más apropiado invertir el orden de las condiciones i) y ii), ya que la condición ii) -aptitud física y mental - es anterior a la condición i) -actitud crítica-, toda vez que la aptitud mental y física es condición necesaria para que la persona pueda desarroltar su capacidad reflexiva. Al enunciar dichas condiciones he preferido, sin embargo, respetar el orden seguido por el autor. 
Dicho esto también podría sostenerse que cuantas más posibilidades tenga frente a sí el agente, mayor es la probabilidad de que pueda escoger la que más le satisfaga. Puede objetarse, sin embargo, que a menudo cuantas más opciones tiene a su alcance el individuo más difícil y angustiante puede volverse el tomar una decisión. Se suma a ello la observación de Gerald Dworkin en el sentido de que mayor cantidad de elecciones - fruto de mayores posibilidades de tomar decisiones en diferentes materias- lleva consigo mayor responsabilidad, lo que es sin duda un coste mayor para el agente (1992: 51), y más aún, como sugiere el autor con ejemplos tales como el de la elección de los esposos, podría llevar a un deterioro en los niveles de bienestar (1992: 55). También el paternalismo al que muchas veces se somenten los agentes racionales muestra que renunciar a ejercer la capacidad de elección puede resultar, en algunos casos, más conveniente (1992: 56).

Estas objeciones, sin embargo, no deberían preocupar al agente racional con capacidad para aplicar criterios claros que le posibiliten establecer un orden de prioridades, y en cualquier caso puede ser que la elección racional sea un mecanismo arduo pero no por ello queda invalidado. Parece razonable admitir que cuantas más opciones tenga a su alcance el agente menos posibilidades existen de que no pueda satisfacer sus deseos y más de que sus preferencias se vean realizadas de un modo más completo o preciso ${ }^{14}$. Si como afirma Raz la autonomía es una cuestión de grado, vale decir que se puede disfrutar de ella más o menos según una serie de condiciones que dependen del contexto; una mayor variedad de opciones disponibles ofrece al agente, prima facie, posibilidades de ser autónomo en mayor grado que si dispusiera de menos opciones.

Puede ser, sin embargo, que para el agente sea irrelevante la mayor parte de las opciones que se le ofrecen, dado que sus preferencias están ya canalizadas o satisfechas por dos o tres opciones claras. Pensemos, por cjemplo, en una vecina de la ciudad de Londres que disfruta de una oferta cultural muy grande, pudiendo elegir, para sus salidas de fin de semana, entre una gran cantidad de conciertos que incluyen desde música de cámara, música sinfónica u ópera hasta conjuntos de rock, grupos de jazz, etc. Para ella, sin embargo, sólo es importante la programación que se ofrece relacionada con autores del barroco italiano, ya que sus preferencias en materia musical se manifiestan claramente en este sentido y sólo asiste a los conciertos en los que se interpreten obras de Arcangelo Corelli, Antonio Vivaldi, Francesco Geminiani o Giovanni Battista Pergolesi, entre otros. ¿Quiere esto decir que la señora del ejemplo podría ser igualmente autónoma - disfrutar del mismo grado de autonomía- si la oferta cultural de Londres se redujera sólo a los conciertos de su preferencia? La respuesta de Raz es que no. Una mayor variedad de opciones disponibles nos permite no sólo escoger una u otra entre muchas, sino contrastar unas

\footnotetext{
is Véase Michael Bayles, Principles of Legislation (1978).
} 
con otras, compararlas, sopesarlas y, en última instancia, nos da siempre la posibilidad de cambiar en algún momento nuestro orden de preferencias.

Por último, la condición iv) de Fallon se refiere a la coerción en tanto sujeción de una persona a los deseos de otra y a la manipulación como la tergiversación de sus decisiones o acciones. La existencia de coerción o manipulación es un obstáculo a la libertad negativa. Pero como señala Raz, coerción y manipulación cercenan la autonomía no por las consecuencias que se deriven de su ejercicio - una persona puede contar con menos opciones a su alcance como producto de la coerción ejercida por otra $y$, sin embargo, seguir disfrutando de una gama considerable de opciones valiosas o incluso tencr la posibilidad de escoger la opción que hará su vida valiosa-, sino que la cercenan porque afectan su valor como capacidad específica para obrar racionalmente de un modo que es - y esto constituye una característica relevante en la teoría de Raz-socialmente aceptado y valorado ${ }^{15}$.

En The Morality of Freedom Joseph Raz distingue tres condiciones para la autonomía: capacidad mental -que equivaldría a la condición ii) de Fallon ${ }^{16}$ - una adecuada variedad de opciones - condición iii) de Fallone independencia - condición iv) de Fallon- (1986: 372). Admite el autor que estas condiciones son complejas, siendo la segunda la que ofrece más matices. Como ya dijéramos, Raz concede un lugar muy especial a esta condición segunda de la autonomía. Las opciones, dice el autor, deben ser «adecuadas»; esto, como apuntara antes al comentar esta misma condición enumerada por Fallon, tiene que ver no sólo con la cantidad, sino con la calidad de las posibilidades de acción que se le presentan al individuo. Raz ofrece un par de ejemplos muy ilustrativos para explicar la importancia que reviste en el ejercicio de la autonomía la existencia de opciones relevantes. Supongamos, nos dice, el caso de una persona que ha caído a un pozo del que no puede salir, pero en el que encuentra comida suficiente para la supervivencia. Su vida en el pozo le ofrece una serie de alternativas: puede dormir durante la mayor parte del tiempo o puede dedicarse a la meditación; puede comer tres veces al día o puede optar por comer sólo una vez al día. El otro ejemplo es el de una mujer que habita en una pequeña isla que comparte con un animal carnívoro que se empeña en cazarla. Esta situación hace que la mujer esté permanentemente en actitud defensiva, concentrando todos sus recursos en el diseño de estrategias para evadir a la bestia (1986: 373-374). En los ejemplos presentados las opciones dadas a los agentes en contextos fijos de elección no

\footnotetext{
15 Raz amplia el argumento recurriendo al ejemplo de casos en los que la coerción es aceptada por sus consecuencias, casos que, según el autor, refuerzan el valor convencional y simbólico de la prohibición de coerción. Véase $\operatorname{Raz}(1986: 378)$.

${ }^{16}$ No se incluye aquî la condición i) de Fallon, ya que Raz rechaza la capacidad de reflexión como condición especifica para la autonomia por entenderla como un elemento innecesario que apela a imprecisas instancias superiores del desarrollo intelectual. Segü Raz, muchas de muestras opciones se configuran a lo largo del crecimiento, siendo aceptadas o elegidas sin que para ello deban someterse a la instancia de la reflexión. Véase Waldron (1989: 1112).
} 
resultan cualitativamente relevantes como para poder hablar de elecciones autónomas. En ambos casos las opciones están limitadas a los distintos modos de satisfacer necesidades básicas, todas las cuales sólo son una condición necesaria, pero no suficiente para poder desarrollar un plan de vida. La mera supervivencia no alcanza para la realización de la autonomía concebida como lo hace Raz. En palabras del autor:

«La elección no debería estar dominada durante la mayor parte del tiempo por la necesidad de proteger la vida que uno tiene. Una elección está dominada por dicha necesidad si todas las opciones excepto una harán bastante improbable la continuación de la vida que uno tiene» (1986: 376$)$.

El énfasis puesto en la existencia de «opciones relevantes» no impide a Raz afirmar que tan intolerable es no poder decidir sobre cosas triviales como no poder hacerlo sobre temas que condicionan fucrtemente nuestra vida. La autonomía implica la capacidad para contraer compromisos o elecciones a largo plazo, así como para desarrollar relaciones duraderas. Pero también implica libertad para efectuar elecciones triviales como la de si peinarme el cabello de una manera u otra o ponerme un pantalón azul o uno rojo (1986: 374).

Se pueden mencionar otros componentes de la autonomía que la definen en su dimensión práctica y que surgen cuando se la analiza a la luz de las capacidades del sujeto racional. Dichos componentes o elementos definitorios son la fuerza de voluntad (strenght of the will), el autoconocimiento o el ser consciente de uno mismo (self-awareness), la capacidad de autoconducirse o trazar una dirección propia (self-direction). La presencia de estos elementos a menudo no es fácil de establecer. Pero en cualquier caso estas condiciones no tienen que ver con la autonomía en sentido kantiano, como propiedad universal que una vez adquirida se separa de las condiciones en que tuvo lugar su desarrollo, sino que están ligadas a ese otro concepto de autonomía, al forjado en la tradición liberal post-kantiana y que agrega elementos relacionados más directamente con el contexto de ejercicio de la autonomía en el cual el individuo desarrolla su plan de vida.

\section{LA PERSPECTIVA COMUNITARISTA}

La autonomía no es un elemento de la teoría moral o política exclusivo de los liberales, sino que se ha convertido en lo que Young llama un tipo ideal, una estructura a la que se da forma de muy diversas maneras. La tradición kantiana de la autodeterminación ha clevado la autonomía a la categoria de virtud en tanto que forma correcta y deseable de obrar; el moldear la propia vida, regularla o dirigirla en una u otra dirección es considerado valioso ${ }^{17}$.

\footnotetext{
17 Véase Young (1986:9).
} 
Según Charles Taylor, la racionalidad - condición necesaria de la autonomíaes para Kant lo que él denomina un bien constitutivo, vale decir la fuente de la moralidad. La racionalidad, en tanto bien constitutivo, sería en Kant la clave que ordena su concepción del bien y el elemento por cuya virtud los bienes son tales ${ }^{18}$.

La relevancia de la autonomía en la teoría moral ha llevado a que numerosos autores, no sólo liberales, hayan teorizado extensamente sobre los elementos en que se puede descomponer el concepto de autonomía. Bajo el marco que ofrece la idea elaborada por Young de autonomía como tipo ideal o virtud - en el sentido señalado más arriba-, una de las concepciones a que se da cabida es la desarrollada en torno a la noción de autorrealización (self-fulfilment), según la cual la autonomía en el sentido kantiano es un elemento necesario pero no suficiente ${ }^{19}$. De esta idea participa Charles Taylor y con él el comunitarismo. En adelante me ocuparé de la versión «débil» del comunitarismo —n el sentido de más proclive a aceptar, con matices, algunos de los presupuestos del liberalismo-, centrándome en la obra de Charles Taylor, aunque creo que también comunitaristas alineados en versiones más radicales de esta corriente - en el sentido de más fuertemente contextualistas o convencionalistas-podrían coincidir con los presupuestos centrales de este análisis.

Algunos autores han planteado que la autonomía no debe entenderse como autorrealización. Para Raz, por ejemplo, la autonomía no es una condición para la autorrealización, ya que autonomía y autorrealización son dos ideales distintos, pudiêndose lograr el segundo de otra forma o por otras vías, inclusive por vías incompatibles con la autonomía, como la manipulación. Según Raz la autorrealizaciôn consiste en el desarrollo de todas las capacidades valiosas que un individuo es capaz de desarrollar, mientras que el agente autónomo tiene la opción de desarrollar todas esas capacidades tanto como la opción de desarrollar sólo alguna o algunas de ellas. Dada esta definición de autorrealización Raz concluye diciendo que una persona no es autónoma si no puede elegir una vida de autorrealización y tampoco lo es si no puede rechazarla (1986: 376). Esto es asi si aceptamos la definición que da Raz de autorrealización, pero podríamos pensar que la definición de Raz no es correcta y que autorrealización no es el desarrollo de todas las capacidades, sino de aquellas que le permitan al agente llevar a cabo su plan de vida. Si tomamos en consideración esta última definición de autorrealización la autonomía se convierte en una condición, si no necesaria, al menos relevante, y es en este sentido en el que los comunitaristas hablan de autonomía como autorrealización.

Antes de comenzar con el estudio de la autonomía como la entiende el comunitarismo repasaré algunos conceptos del análisis comunitarista que influyen de manera dccisiva en su concepción de la autonomía personal. Dichos

\footnotetext{
1* Véase Taylor (1996: 109)

19 Véase Young (1986: 11).
} 
conceptos son elaborados partiendo de la oposición comunitarista a los presupuestos del liberalismo.

\subsection{El comunitarismo y la crítica al atomismo liberal}

Según el comunitarismo, y según la visión de Taylor, una vida no inscrita en un marco referencial - framework - capaz de otorgar un horizonte de significado es una vida vacía de espiritualidad y de sentido. El contexto de interacción es relevante en la concepción de Taylor porque sólo a través de la interacción dentro del marco histórico-espacio-temporal el sujeto es capaz de experimentar sensaciones vitales - amor, odio, miedo, ansiedad-y transmitirlas. La búsqueda de identidad individual no puede realizarse sin un planteamiento histórico sobre las «condiciones trascendentales» en que se encuentra el sujeto, y esto sólo es posible en un espacio común de interacción, de intercambio con quienes comparten el mismo espacio social y cultural ${ }^{20}$. Sólo así es posible acceder a la gama de sensaciones que experimenta una persona y que forman su universo de identidad. Para Taylor resulta inconcebible la idea de un individuo no sujeto a las pautas propias de un contexto dado; un sujeto sin un marco de referencia - framework- quedaria fuera del espacio de interacción, no le seria posible intervenir en contextos sociales como lo hacen quienes sí tienen un «marco referencial» previo y sería considerado un caso patológico de crisis de identidad (1989a: 31-35).

Tal vez podamos comprender mejor este último punto si ampliamos la descripción del individuo que tiene en mente Taylor. Según éste, el individuo moderno responde a la noción de un self - yo consciente- ${ }^{21}$ «multifacético», caracterizado por la razón desvinculada - desengaged reason-, el autoconocimiento - self-exploration - y el compromiso - personal commitment- (1989a: 211). Estas tres características merecen una breve mención. Taylor llega a ellas después de haber realizado un recorrido a lo largo de la historia de

${ }^{2}$ Podemos añadir a estas consideraciones de Taylor el punto de vista de MacIntyre sobre la «crisis de la objetividad moral». Según el análisis de Maria Matteini, dicho autor considera que el individuo contemporáneo habria alcanzado un estado de shipertrofia de la subjetividad», entendida ésta como mera voluntad que obra sin ceñirse a razones o principios, como seria el caso del "yo emotivista" - consideración ésta que es a su vez criticada por Matteini al entender que el emotivismo lejos de estar reñido con su entorno social «es un producto de éste, del condicionamiento social, cultural y político»-.. El sujeto moral quedaria asi reducido al user emotivista» carente de cualquier tipo de identidad social (Matteini 1995: 38). La propuesta de Taylor plantea precisamente una reconducción de este «yo emotivistas hacia contextos de moralidad. Intenta salvar de este modo la, a su entender, equivocada posición que el liberalismo confiere al sujeto cuando lo ubica por encima de los horizontes de sentido (sobre este tema ver introducción de Carlos Thiebaut a La ética de la autenticidad, Taylor, 1994:25).

"No existe en castellano una palabra con la que se pueda traducir de manera precisa la noción implícita en la palabra inglesa self. Aunque se ha traducido en algunos casos como «yo» $o$ «sujeto» tal vez se pueda ganar en precisión al entenderlo como yo consciente. 
la filosofía. Lo que se ha traducido como razón desvinculada -o tal vez sería más preciso razón «desenganchada» en el sentido de independiente, liberadase desarrolla primeramente con Descartes, que sitúa la fuente de la moral en el propio individuo. Una vez que la razón ha sido elevada a la categoría de referente moral, el individuo ya no puede seguir atado ni a los mandatos de fuerzas sobrenaturales ni al cosmos; la vida de cada persona pasa a ser diseñada según los dictados de la propia razón (1989a: 155). La segunda característica, el autoconocimiento, está íntimamente ligada al individualismo: la persona pasa a ser el centro de exploración e interés. El individuo «radicalmene libre» o independiente de los condicionamientos externos es capaz de autodeterminarse a través de lo que para Locke seria «voluntarismo teleológico" (1989a: 171). El sujeto que se concibe a sí mismo de esta manera, como radicalmente independiente y capaz de rehacerse a sí mismo, es identificado por Taylor como «yo puntual» - punctual self-, que en la concepción lockeana representa una «visión radicalmente subjetivista de la persona» (1989a: 172). La separación del individuo respecto de determinantes externos genera una conciencia independiente capaz de autocontrol. Este proceso racional-individual demanda a su vez una actitud reflexiva del agente (1989a: 174). La última característica, el compromiso personal, sobrevendría cuando el individuo independiente y autoconsciente asume compromisos que lo hacen responsable frente a la comunidad. El compromiso personal refleja la clásica idea de responsabilidad, que es la contracara de la autonomía. En la trayectoria histórica trazada por Taylor se señala que el calvinismo y el puritanismo contribuyeron a reforzar esta idea de compromiso personal (1989a: 194).

Como apunta Carlos Thiebaut en Los límites de la comunidad, los comunitaristas han criticado el liberalismo por postular una neutralidad imposible de sostener a menos que se acepte la «psicologia moral del empirismo clásico» (1994: 24). Alasdair MacIntyre, otro conocido filósofo comunitarista, sintetiza su crítica al empirismo oponiéndolo a la tradición aristotélica de interpretación de los hechos a través de las nociones del bien y de la virtud. El empirismo se aparta de estas nociones, abandona la interpretación y la teoría para destacar el hecho y la experiencia en tanto que descripciones sensoriales. Este escenario, que MacIntyre considera poco fructifero, es el que haría posible la neutralidad respecto de cualquier teoría del bien.

Es sabido que el empirismo moderno se inicia con el realismo de Hume, para quien no hay vicios o virtudes a la luz de una teoría del bien, sino sólo pasiones o sentimientos que expresan su aprobación o desaprobación respecto de ciertos hechos. De este modo rechaza toda explicación teleológica. La única instancia de apelación para los juicios morales es, según Hume, el buen sentido de los hombres ${ }^{22}$ y de las mujeres. Según la interpretación que el comunitarismo realiza de la neutralidad liberal, sin presuponer el empirismo de base humeana resultaría imposible afirmar que el individuo es capaz de autodeterminarse,

2. Véase Macintyre (1985: 230-231). 
en el sentido de decidir imparcial y descontextuadamente, sin ningún tipo de condicionamientos externos al sujeto. Una vez afirmada la individualidad del sujeto se presupone que la capacidad de elección viene dada en cada persona, vale decir que habría que sostener - para dar sentido a los postulados del liberalismo-, que la autonomía no es una capacidad a desarrollar, pues si así fuera deberíamos aceptar que existen otros innumerables factores -incluida una determinada concepción del bien-que podrían coadyuvar a ese desarrollo.

Sostiene el comunitarismo que la capacidad absoluta de autodeterminación del individuo lleva a admitir, a su vez, ta posibilidad de un pluralismo radical o extremo que desembocaría en el atomismo liberal. La identidad desvinculada del contexto implica la existencia de sujetos independientes de la sociedad. Un sujeto que puede escoger entre concepciones del bien diversas se ubicaría por encima de los valores ${ }^{23}$ sin tener con el contexto - social, cultural, etc.y con el lenguaje una relación constitutiva - ontológica - que determine su capacidad de elección. En este sentido afirma Taylor que el atomismo produce a su vez fragmentación ${ }^{24}$.

\subsubsection{La crítica a la tesis de la primacía de los derechos}

El lugar preponderante otorgado a la autonomía personal como presupuesto moral, junto a la preocupación liberal respecto de la igual consideración que deben recibir los individuos en la persecución de sus propios intereses, encuentran una de sus manifestaciones más importantes en la primacía de los derechos respecto de concepciones particulares del bien. Los derechos, en la medida en que recogen el valor de la autonomía, garantizan que las personas puedan actuar conforme a sus propios intereses sin que éstos deban estar condicionados por una particular concepción del bien ${ }^{25}$. La ética comunitarista, en cambio, apunta al reconocimiento de la comunidad como unidad, con referencia a la cual debe plantearse cualquier construcción individual o grupal. En su crítica a la primacía de los derechos Taylor atribuye un significado preciso a las teorías que defienden dicha primacía (1990: 107). Estas teorías considerarían, según el autor, que la adjudicación de ciertos derechos es un principio básico - como postularan Hobbes o Locke-, ya que a partir de los mismos el individuo autosuficiente puede ver realizada su autonomía. Los liberales inferirían del hecho del individuo aislado los derechos cuya primacía defienden. La crítica de Taylor indica que los liberales estarían incurriendo en alguna especie de falacia naturalista, pues pretenden inferir consecuencias normativas del hecho

2. Véase Taylor (1994: 25).

${ }^{24}$ Véase Taylor (1994: 138).

${ }^{2}$ La primacia de los derechos tiene en la teoria de John Rawls un doble propósito. En primer lugar asegura que se otorgue igual valor a los intereses de todas las personas, y en segundo lugar desvincula los planes de vida personales de cualquier concepción particular de la vida buena. Para la crítica a la teoría de la primacía de los derechos de Rawls, véase Kymlicka (1989: 21-43). 
del individuo aislado, sin advertir que si las cuestiones normativas no dependen de hechos bien pueden relacionarse con postulados diversos acerca de los individuos y la sociedad. En otras palabras, el individuo como unidad física natural no tiene necesariamente que ser la fuente que abastece o nutre la vida moral de la persona, o al menos de lo primero no se deriva lo segundo. El autor caracteriza la teoría de los derechos como una concepción reductivista -que pretende ofrecer una teoría del bien con alcance universal-y principalmente utilitarista, todo lo cual sería una simplificación de lo que en realidad es una compleja diversidad cultural que alimenta la vida moral de los individuos.

Para sustentar su crítica al individualismo Taylor se vale de Aristóteles y de su defensa de la esencia social y política de las personas, sosteniendo que

«[...] vivir en sociedad es una condición necesaria del desarrollo de la racionalidad en algún sentido de esta facultad, ya sea de llegar a ser un agente moral en el sentido pleno del término o un individuo plenamente responsable y autónomo" (1990: 110).

La propuesta de Taylor para la fundamentación de los derechos se basa en conceder valor y, en consecuencia, respeto a determinadas capacidades humanas desarrolladas socialmente, lo que iría acompañado de la obligación de «estimularlas y ampliarlas»:

«El hecho de afirmar el valor de la capacidad humana para formar convicciones morales y religiosas tiene mucho mayor alcance que la adjudicación del derecho a las propias convicciones» (1990: 112).

También Michael Sandel defiende una concepción social sustantiva de los derechos al afirmar que cuando se garantiza, a través de los derechos individuales, que una persona pueda llevar a cabo ciertas prácticas, lo que debe evaluarse no es la sola capacidad del agente para ejercer su voluntad, sino el valor que se asigna a las prácticas en cuestión. Sobre este punto volveré más adelante.

Según Taylor, para defender la tesis de la primacía de los derechos habría que postular también la del atomismo social, según la cual los individuos son autosuficientes fuera de la sociedad. De lo contrario, y si esto como parece no es plausible, cabe entonces dar lugar a las tesis sociales según las cuales el individuo sólo puede desarrollar su autonomía $-\mathrm{y}$ ejercitar los derechos que de su condición de agente autónomo se derivan - en el marco de cierto tipo de culturas en las que se verifica la condición de libertad ${ }^{26}$ :

26 Entre estas dos concepciones - la del individualismo liberal y la del comunitarismo- puede intercalarse la idea recientemente desarrollada por Raz sobre la fundamentación de los «derechos democráticos» - como el derecho a votar, el de libertad de asociación política o incluso el derecho de libertad de expresión-. Según $\mathrm{Raz}$, el liberalismo ha basado estos derechos en una concepeión individualista de los derechos como intereses - individuales- cuando en realidad, dice Raz, lo 
«[...] la identidad del individuo autónomo y autodeterminado requiere una matriz social que reconozca, por ejemplo, a través de una serie de prácticas, el derecho a la decisión autónoma y que defienda que el individuo tiene voz en la deliberación sobre la acción pública» (1990: 123).

Esta afirmación es formulada por Taylor en términos muy parecidos a los que utiliza Raz cuando afirma que el ser autónomo sólo tiene sentido en un contexto en el que la autonomía es promovida como condición ineludible para el desarrollo de los planes de vida individuales. Taylor pone el acento en esa dimensión de la autonomía que, pretendiendo reconocer los presupuestos kantianos, crea unas condiciones dependientes de la cultura y el contexto en que el individuo autónomo actúa. A esta tesis, y a sus distintas formulaciones, me referiré más adelante al hablar sobre la contextualidad de la autonomía.

\subsubsection{La crítica a la libertad negativa}

Otra de las críticas del comunitarismo al concepto de autonomía como lo entienden los liberales es la vinculada a la distinción entre libertad positiva y libertad negativa. Si el liberalismo siempre ha defendido la concepción de libertad negativa sin preocuparse tanto por la de libertad positiva, los comunitaristas parecen hacer lo contrario. La primera, como vimos ya, se define por la capacidad de un individuo para actuar, resultado de la no intervención de terceros para que lo haga; para satisfacer la condición de libertad negativa no es necesario que dicha capacidad se ejercite efectivamente, basta con que el sujeto esté en condición de hacer uso de ella. Taylor define este sentido de autonomía como un "concepto de oportunidad», dado que la idea es que cl sujeto sea libre para actuar y se den las condiciones para que lo haga sin indagar en cuál es la conducta efectivamente adoptada por la persona en cuestión (1992: 213). Ahora bien, cuando el sujeto, haciendo uso de esa capacidad que le otorga la libertad negativa, se decide a actuar, los defensores de la libertad negativa restringen la acción al ámbito estrictamente individual, en el que sólo al agente y su esfera íntima incumben las motivaciones y ponderaciones que lo llevan a adoptar la decisión de actuar en un determinado sentido.

El punto más conflictivo respecto de la libertad positiva $\rightarrow$ generalmente identificada con la autonomía- ${ }^{27}$ es el que se refiere a la capacidad de intervenir que en nombre de esa misma libertad pueda otorgarse al Estado como protector o propulsor de determinados fines o valores. En verdad, cuando concedemos valor a la efectiva capacidad del individuo para actuar, el propiciar o ayudar

que hace que estos derechos gocen de la protección de que gozan no es el que sean de interés para un individuo, sino el que lo sean para el bien público (1995).

${ }^{27}$ Véase Laporta $(1983: 26)$. 
a la libertad positiva puede querer decir dos cosas. Por un lado, en sentido débil, se trata de ayudar a adquirir o desarrollar la autonomía en tanto capacidad, vale decir contribuir a la formación del ser humano racional e independiente. En este sentido actuarían las maestras o los padres cuando estimulan a niñas y niños para que en el uso de su inteligencia sean capaces de resolver los desafios del aprendizaje. También el Estado neutral actúa muchas veces no sólo removiendo obstáculos, sino ayudando al individuo a usar su capacidad conforme a las elecciones individuales; así to hace cuando, por ejemplo, lleva a cabo programas educativos que ayudan a alcanzar los objetivos individuales de una manera plural y tolerante. Pero la libertad positiva admite también una interpretación en sentido fuerte, según la cual el promover el ejercicio de la autonomía lleva implícito el hacerlo conforme a como la autonomía es concebida en contextos específicos.

Si se atiende a este doble aspecto de la libertad positiva tal vez puedan eliminarse algunos de los riesgos que ella encierra, sin por ello negar la relevancia de la libertad entendida como capacidad efectiva de la persona para decidir y actuar, es decir, en palabras de Isahia Berlin, para ser su propio amo. Raz admite que la libertad negativa es relevante sólo en la medida en que sirve a la libertad positiva:

«Las discusiones en torno a la libertad negativa y la coacción normalmente se centran en el supuesto de coaccionar a la gente para que realice o evite acciones especificas. Éste es el contexto natural de la coacción, que, sin embargo, puede ocultar su significado moral y ha llevado, en alguna ocasión, a una obsesión ciega con la eliminación de la coacción. La libertad negativa, es decir, la ausencia de interferencias coactivas, es valiosa en la medida en que resulta útil para la libertad positiva y la autonomía» (1988: 410).

De manera similar, para Taylor el concepto de autonomía reside principalmente en la libertad positiva. La libertad negativa no garantiza, según cl autor, la autodeterminación del individuo, ya que para ello se requiere de una teoría del bien así como de una definición sobre la naturaleza humana. Critica a los liberales por refugiarse en la libertad negativa ante el temor de que concepciones positivas puedan abrir la puerta a posturas totalitarias (1992: 215). Este riesgo totalitario de la libertad positiva parece ir asociado a su segundo sentido según lo apuntado más arriba, vale decir que se refiere a la posibilidad de intervencionismo o paternalismo estatal que podría llevar a la promoción de una única y determinada alternativa valiosa. ¿Pero cuál de los dos sentidos de libertad positiva antes apuntados sostienen los comunitaristas? La promoción de un concepto de autonomía $\rightarrow$ y de libertad positiva - fuertemente ligado al contexto en que se desarrolla parece estar presente en la ética de la autenticidad de la que habla Taylor y a la que me referiré en el próximo apartado.

Susan Hurley retoma la concepción de Taylor y la describe diciendo que efectivamente la libertad como capacidad de autodeterminación debe abrir 
la puerta a cuestiones como las de la naturaleza humana o la naturaleza del «self», aunque en este terreno pueda resultar fácil arrastrar al individuo de la mano de posturas totalizadoras (1989: 352). Hurley coincide con Taylor en adoptar una concepción de autonomía como valor sustantivo, vale decir que defiende la idea de autonomía como libertad positiva ${ }^{28}$, terreno en el que se hace necesario afrontar la elección de una teoría del bien tanto como criterios de identidad personal. Hurley parece apartarse de los comunitaristas al decantarse por una concepción que recoge las características sobresalientes del concepto kantiano de autonomía - destacando el valor per se de la misma-, mientras que, como vercmos en el próximo apartado, los comunitaristas conciben la autonomía como instrumento para la consecución de otros valores. No obstante, en algunos puntos la postura de Hurley resulta ambigua. Según la autora, la autonomía ocupa un lugar superior en la escala de valores sustantivos, pero no tendría sentido como valor aislado (1989: 350), lo que sugiere la necesidad de contrastar su valor con el de los fines perseguidos.

Hurley elabora un concepto de autonomía como autodeterminación valiéndose de la idea de que existen dentro de la sociedad divisiones horizontales y divisiones verticales. Las primeras reflejan la diversidad sustantiva y los conflictos que se le plantean a cada individuo cuando confronta sus distintos deseos y valores, mientras las segundas ponen de manifiesto las distinciones entre individuos y la deliberación que se entabla entre ellos (Harley, 1989: 317).

Las teorías que respectivamente adoptan una u otra de estas concepciones padecerían, según Hurley, de problemas. Las «teorías verticales», como es el caso del contractualismo, dejan de lado las distinciones de valor y de verdad, mientras que las teorías horizontales, como serían, según la autora, las de Platón o Marx, encierran el peligro de acabar cercenando la autonomía individual (1989: 318). Sin embargo, propone no renunciar a ninguno de los dos enfoques, tomando ambas distinciones como fundamentales y amalgamándolas en lo que da en llamar «teorías sociales de estructura completa» (fully structured). Como ejemplos de este tipo de teorías omnicomprensivas cita las de Mill, Sen y Taylor. Efectivamente, como veremos más adelante, Taylor, al enunciar las condiciones a la ética de la autenticidad, no renuncia a la autonomía, pero pretende integrarla con valores sustantivos. Ambas pretensiones, la de Hurley y la de Taylor, parecen insostenibles. No me detendré aquí en la propuesta de Hurley, sino que intentaré demostrar las dificultades que presenta la tesis de Taylor.

${ }^{2 \pi}$ Hurley desarrolla esta concepción de autonomta en relación con la democracia, uno de cuyos fines seria el de propiciar las condiciones sociales y la deliberacion capaces de hacer posible wthe virtue of autonomy» (1989:351). 


\subsection{Las condiciones de la autenticidad: análisis y critica}

A la fragmentación que resultaría del atomismo liberal Taylor responde con la «ética de la autenticidad». La ética de la autenticidad es un intento por recuperar una ética comprensiva que reconozca los valores sustantivos supuestamente contenidos en lo que Taylor denomina horizontes de sentido. Las condiciones de la autenticidad, según las enuncia el autor, son las siguientes:

«A) [la autenticidad] entraña: i) creación y construcción así como descubrimiento, ii) originalidad y con frecuencia iii) oposición a las reglas de la sociedad e incluso, en potencia, a aquello que reconocemos como moralidad.

B) [pero también] requiere: i) apertura a horizontes de significado (pues de otro modo la creación pierde el trasfondo que puede salvarla de la insignificancia), y ii) una autodefinición en el diálogon (1994: 99).

Las condiciones A) y B) de Taylor pueden entenderse como un intento por combinar dos vertientes distintas de la idea de autonomía. Por un lado, siguiendo la concepción kantiana, se concede a la autonomía valor en sí misma, independientemente de los fines a los que pueda servir o de los bienes o acciones que pueda procurarnos. Esta concepción de la autonomía como intrínsecamente valiosa ${ }^{29}$ pone el acento en el agente como decisor independiente y libre (vale decir que lo que interesa al concepto es la evaluación que hace el agente -agent evaluation-). Por otro lado, puede entenderse que la autonomía es valiosa en tanto sirve para alcanzar determinados bienes considerados valiosos. En este sentido se otorga a la autonomía valor instrumental como herramienta que hace posible la obtención o ejecución de cosas o actos cargados de valor, deseados; la autonomía estaría así en función de una elección valiosa $o$, lo que es lo mismo, de unos fines determinados. La autonomía se reviste de valor en tanto son valiosos los actos de que es objeto (lo que se evalúa es el acto -act evaluation-), quedando en un segundo plano el agente en su calidad de agencia autónoma (Young 1986: 21).

Podemos ver en las condiciones establecidas por Taylor elementos de los dos puntos de vista antes señalados. La ética de la autenticidad encerraría la pretensión de síntesis de principios universales respecto del valor de la autonomía como presupuesto para la elección individual y de pautas relativistas que matizarían la elección individual al quedar ésta determinada por un hori-

${ }^{29} \mathrm{La}$ idea de autonomía como valor intrínseco admite a su vez distintas concepciones que Young resume, a grandes rasgos, en dos (1986: 27): por un lado, hay quienes la consideran un valor en sí mismo sin necesidad de que exista para ello quien le otorgue valor (Moore); por otro lado, están quienes hablan de que algo - la autonomía en este caso- es valioso si merece la pena tenerlo o poseerlo por sí mismo (Lewis). La diferencia radica principalmente en establecer si puede hablarse de valores alli donde no hay quien evalúe. Entre los partidarios de la segunda tesis se encuentra también Von Wright, a cuya posición se hace referencia en la nota 31. 
zonte de sentido para la vida virtuosa ${ }^{30}$. Cabe, sin embargo, preguntarse sobre la efectiva posibilidad de reconciliar dos supuestos ético-normativos tan excluyentes: si la autonomía es valiosa en sí misma entonces por definición no puede ser valiosa por los fines que persigue, y a la inversa, si son los fines los que le confieren valor entonces no es valiosa en sí misma.

Empecemos por analizar los elementos de la primera condición. Al enunciar en A.i) la creación y construcción, Taylor pone cl accnto en cl individuo, en el valor que su autonomía encierra en sí misma con independencia de los resultados que se consigan. Se habla así de creación, pero no de unos determinados resultados producto de esa creación. Como dijera más arriba, esto podemos conectarlo con la idea de la autonomía como intrínsecamente valiosa. Cuando algo es deseado o querido con independencia de los beneficios colaterales o de los resultados a que me pueda conducir la posesión de ese bien deseado podemos decir entonces que se trata de un bien valioso en sí mismo, o intrínsecamente valioso ${ }^{31}$. Puedo, por ejemplo, sentirme satisfecha pintando cuadros aun sabiendo que el valor artístico de mis pinturas es escaso o nulo; o puedo apreciar enormemente el dedicar varias horas al día al estudio de las matemáticas aun cuando sepa que esta actividad no es rentable para mí o que me distrae respecto de mis responsabilidades. Del mismo modo, el ser autónoma o actuar autónomamente puede ser valioso en sí mismo sin tener necesidad, a estos efectos, de determinar el valor de los resultados de mi obrar autónomo.

Este primer punto, sin embargo, expuesto aisladamente, presenta problemas que no pasan desapercibidos ni a liberales ni a comunitaristas. Young, citando a Feinberg, apunta a una distinción que pone de manifiesto uno de esos pro-

: Taylor no se detiene a analizat el concepto de virtud que utiliza, aunque de las menciones realizadas en Fuentes del yo (1996) cabe pensar que recoge el concepto utilizado por Maclntyre - como lo hace también cuando alude a la idea de tradición. Según Alasdair MacIntyre la virtud consta de al menos tres momentos conceptuales intemos (Matteini 1995: 82). El primero es la práctica en tanto práctica social o interacción cooperativa entre los individuos, que facilita la vida común y el logro de un bien común. La colaboración virtuosa vendría a ser en MacIntyre algo así como el antidoto al aislamiento del ryo emotivistas (1995; 85; ver nota 19). En segundo lugar, se enumera la kunidad narrativa de la vidas; la vida es concebida como un todo y la virtud se alcanza a través de la búsqueda de la vida buena. Esta segunda caracterización de la virtud comprende y supera a la anterior, ya que la práctica adquiere una perspectiva teleologica que se extiende a toda la vida del individuo. Finalmente, el tercer momento es la tradición, criterio que llena de contenido Ia idea de vida buena proveyéndola de una historia común particular (1995: 90).

\$) Von Wright explica la noción de valor intrínseco del siguiente modo. Supongamos que me ofrecen algo $x$ que no poseo. Debo considerar si me apetece aceptar $x$ o rechazarlo. En mi consideración respecto de si voy o no a aceptar la oferta, no deben cntrar apreciaciones que tengan que ver con las consecuencias o efectos que se puedan derivar de aceptar $x$, ni con las acciones que me va a demandar su aceptación o posesión, ni con las consecuencias de dicha posesión. Si entonces, habiendo dejado de lado todo cálculo oportunista aún elijo aceptar $x, x$ es querido en sí mismo. Si prefiero no aceptarlo, $x$ no es querido en sí mismo. Y si no tengo ringuna preferencia al respecto $x$ es indiferente en sí mismo (1963: 103). 
blemas; distingue entre la «satisfacción del propio bien» y la «contribución al bien». En función de esta distinción el autor destaca que los resultados de ciertas acciones llevan a pensar que la mera satisfacción del propio deseo de autonomía no siempre debería considerarse valioso. Para utilizar un ejemplo clásico podría decirse que Adolf Hitler se sentía realizado en su plan de vida y veía plenamente desarrollada su autonomía personal, lo cual contribuía a su propio bien; no lo hacía, sin embargo, al bien ${ }^{32}$. Ésta es una de las críticas del comunitarismo a la concepción de la autonomía como intrínsecamente valiosa: ¿puede seguir predicándose la autonomía como un valor aun cuando su ejercicio produzca actos disvaliosos?, ¿puede la autonomía ser valiosa cuando las opciones escogidas no lo son? Al plantear esta pregunta debe quedar claro en primer lugar que ya no estamos moviéndonos dentro de las coordenadas de racionalidad e independencia que estructuran la autonomía kantiana. Entramos, en cambio, en el ámbito de los elementos o condiciones que se han ido anexando al concepto kantiano. $Y$ entre estas condiciones, como hemos visto, está la de una adecuada gama de opciones. Cabe entonces preguntarse si la elección de una determinada opción puede ser cescalificada por inadecuada o disvaliosa, al punto de que tal clección - la elección de la acción disvaliosapueda volver disvaliosa la autonomía como capacidad. Tal vez la cuestión no deba plantcarse de este modo. Cuando se sostiene que la autonomía es valiosa en sí misma con independencia de las elecciones a que pueda llevar, lo que se está valorando es la libertad. El punto relevante es qué valor concedemos a la libertad. Que el uso de esa libertad pueda llevar a la realización de actos que consideramos moralmente desacertados no invalida el valor concedido a la libertad. Tal vez convenga tener en cuenta estas dos instancias de la evaluación para evitar caer en el falso problema de creer que podemos descalificar la autonomía porque con ella se puede llegar a resultados no deseados. La autonomía, en tanto ejercicio de la propia libertad, puede ser defendida aun cuando se condenen actos que - como el genocidio perpetrado por Hitlerpresuponen el respeto a la autonomía personal. En todo caso podremos decir que algunas personas hacen un uso inadecuado de su libertad al utilizarla para llevar adelante acciones o planes de vida que desaprobamos. De ello no se sigue que la autonomía pierda su valor. De un modo similar estamos dispuestos a defender el derecho a la vida aun cuando creamos que algunas personas tienen planes de vida que merecen nuestro reproche o nuestra sanción.

No obstante, la pregunta así formulada - zpuede la autonomía ser valiosa cuando las opciones escogidas no lo son?- conduce a engaño, dado que no tiene en cuenta la distinción ya mencionada entre dos momentos distintos: el de la autonomía en sentido kantiano como capacidad universal y el del ejercicio de la autonomía en un contexto social determinado. En el primer sentido la autonomía como capacidad de racionalidad e independencia no puede ser cuestionada por consideraciones contextuales o valorativas. Ahora bien,

\footnotetext{
"2éase Young (1986: 15).
} 
cuando introducimos las opciones como condición de lo que llamamos concepto moderno de autonomía y además, siguiendo a Raz, decimos que la gama de opciones no puede ser cualquier gama de opciones, sino una adecuada, entonces sí haccmos intervenir consideraciones contextuales y valorativas. Raz explícitamente rechaza las opciones disvaliosas, ya que éstas transforman en disvalioso el plan de vida de la persona que las elige. En consecuencia no habría razones para que el Estado deba promover opciones de este tipo, tomando partido Raz por una solución perfeccionista:

4[..] mientras que la autonomia es compatible con la presencia de malas opciones, éstas no contribuyen en nada al valor de la autonomía. De hecho, el elcgir autónomamente lo que es malo hace que nuestra vida sea peor de lo que podría ser una vida comparablemente igual, aunque no autónoma» $(1988: 412)$.

Como veremos al analizar la condición B) de la autenticidad, también Taylor confiere valor a la autonomía en tanto ésta sirve para la elección de opciones valiosas, aunque su formulación es diversa.

A esta crítica de Taylor sobre el valor de la autonomía cuando su resultado es la elección de opciones disvaliosas se suma una segunda objeción: si la autonomía fuera valiosa per se debería ser un bien deseado por todos sin excepción y, sin embargo, no parece ser éste el caso; muchas personas en determinadas circunstancias podrían estar dispuestas a prescindir de su autonomía. Taylor dirige una tercera crítica a la equivalencia que establece la tradición kantiana entre agente racional y agente autónomo (1992: 385). Dado que la filosofía moral liberal se basa en una teoría de la libertad, dice Taylor, no debería ignorar que la agencia racional no puede ocupar el universo moral de la persona. Dicho en otras palabras, lo que el autor quiere expresar es que el agente moral es algo más que un agente racional, la racionalidad sería sólo un componente de la persona moral.

El enunciado A.ii) postula la originalidad, que es para los comunitaristas el espacio propio de la autodeterminación. Sin embargo, debemos escudrinar el pensamiento comunitarista para saber si este potencial subjetivo de originalidad es independiente o si, por el contrario, se define exclusivamente a través de la interacción con el espacio exterior, con el contexto histórico-social receptor de la originalidad individual. Esto nos lleva directamente al punto A.iii), en el que Taylor, asumiendo una postura aparentemente contradictoria con lo que es el núcleo determinista del comunitarismo, admite el desarrollo individual hasta el punto del enfrentamiento con las pautas comunitarias. Sin embargo, esta afirmación puede no resultar contradictoria si tenemos en cuenta que el inciso A.iii) no habla de cambio de las reglas de la sociedad ni de cambio de las pautas de moralidad de la sociedad. Vale decir que no introduce la posibilidad de que los individuos reformulen las reglas cuyo significado viene dado por procesos históricos largos hasta llegar a formar los horizontes de sentido. Taylor sólo admite la oposición individual a dichas reglas, lo que equi- 
valdría a decir que admite la diversidad o la pluralidad de puntos de vista, pero en cualquier caso el marco de referencia siempre viene dado y sirve de referencia aûn y precisamente cuando nos oponemos a êl. Esto de ningún modo significa replantear o reformular las pautas comunitarias dadas, sino simplemente tolerar formas distintas a las establecidadas, las que a su vez se definen con referencia a estas últimas. Para mantencr una postura coherente con el postulado B), en cuanto a la sujeción a horizontes de significado y la autodefinición en el diálogo, la única relevancia que puede otorgarse a la disidencia es la de ser testigo de la tolerancia hacia posturas diversas, sin que los horizontes de sentido dejen de ser hegemónicos como parámetro moral. Tal cosa no significaría la reformulación de los horizontes de sentido ni de las pautas morales comunitarias. Este tipo de reformulación sólo podría concebirse, en el ideario comunitarista, a través de períodos históricos largos y de un cambio en el lenguaje y en la narrativa propios de una cultura. De modo que A.iii) debe entenderse en sentido débil como la capacidad del indi. viduo para autodefinirse por oposición a las reglas sociales de referencia, pero en el marco y dentro de las posibilidades que ellas le brindan ${ }^{33}$.

"Uno de los problemas que se pueden plantear a la etica como autenticidad es la brecha que muchas veces se produce entre los impulsos, pasiones, gustos y deseos en general y las preferencias de segundo orden. Taylor recurre a esta distinción entre deseos de primer orden $y$ deseos de segundo orden utilizando la propuesta hecha en tal sentido por Harry Frankfurt. Lo que distingue a los seres humanos, dice Frankfurt, son los deseos de segundo orden seyún los cuales queremos tener cierto deseo (de primer orden) o queremos que cierto deseo se transforme en voluntad (will), en cuyo caso estariamos frente a lo que él denomina voliciones de segundo orden (1971: 10). Admite también Frankfurt que en caso de conflicto entre deseos de segundo orden podriamos apelar a deseos o voliciones de orden superior y así sucesivamente hasta crear un sistema complejo de preferencias. Taylor retoma estos conceptos para formular la distinción entre el «mero sopesador» (simple weigher) y el «evaluador fuerte» (sirong evaluator). El primero sólo se interesa por los resultados de la acción en la medida en que éstos satisfagan sus preferencias. El segundo, en cambio, evalúa sus motivaciones según la calidad de sus deseos (1985: 16).

La aparente correspondencia entre los deseos de primer orden y el mero sopesador, por un Iado, y los deseos de segundo orden y el evaluador en sentido fuerte, por otro, no es sin embargo tan clara. Por ejemplo, dice Taylor, alguien puede tener que decidir entre si pasar sus vacaciones en el norte a en el sur de Europa. El desco de ir al norte va acompañado por el entusiasmo por conocer nuevos sitios y disfrutar de un entorno rico en parques naturales, lagos y una flora desconocida para ella. El deseo por ir al sur está motivado por las ganas de disfrutar de la playa, del mar y del sol. Ambas motivaciones - la de ir al norte y la de ir al sur- se basan en deseos de primer orden, y el agente tiene que resolver el conflicto en un sentido u otro, sopesando sus deseos. En ningún caso se trata de realizar una evaluación en sentido fuerte, ya que no hay en esta decisión cuestiones valorativas que el agente deba considerar; en efecto, tendrá que priorizar un deseo sobre otro, pero no estará sometiendo sus motivaciones a consideraciones morales de ningún tipo. A pesar de ello el conflicto refleja que las evaluaciones débiles -las del simple sopesador - no tienen por qué ser meramente cuantitativas, sino que pueden tener un componente cualitativo para cuya resolución debo apelar a deseos de segundo orden, lo que no obsta a que la elección siga siendo una mera cuestión de preferencias (1985: 17). Esto, dice Taylor, muestra que no todos los casos en que intervienen deseos de segundo orden son casos de evaluación en sentido fuerte. Como en el cjcmplo en cuestión, puede ser que se trate de una incompatibilidad fáctica y contingente que nos obliga a priorizar un deseo 
La condición B.i) es la que introduce lo que quizás sea el punto más controvertido y característico del comunitarismo que Taylor ha desarrollado extensamente en su obra Sources of the Self ${ }^{34}$. Al recurrir a los horizontes de sentido plantea la tesis según la cual el agente, para constituirse como ser autónomo y reconocer su identidad, debe orientarse en un espacio moral que otorgue significado a su elección. Los horizontes de sentido deben a su vez ser reconocidos y protegidos socialmente. Esto no parece que pueda lograrse si no es a través de un Estado perfeccionista. Taylor estaría apoyando la tesis social según la cual la neutralidad liberal, y más concretamente el Estado neutral, no es el adecuado para defender y promover el entorno que nos ayude en la elección de opciones valiosas. De modo que el Estado perfeccionista debe intervenir para que, limitando y configurando las opciones valiosas, promueva a su vez la autodeterminación ${ }^{35}$. Ésta requiere de la autonomía en tanto medio para la confirmación y reproducción de los valores sociales. De este modo se priva al concepto de autonomía de su valor intrínseco primario, otorgándole en cambio valor instrumental que cuanto menos limita el primero. En palabras de Taylor, al decir que el individuo se mueve en horizontes de valor que le son dados, el autor está diciendo también que la elección que realiza cada persona cuando se autodetermina, y la propia capacidad de elección, no tienen otro valor más que el que tienen las opciones por las que se inclina (1994: 74). Esta idea entronca con la de articulación, presente también en la teoria de Taylor. Por oposición a las ćticas inarticuladas - entre las que se incluye el liberalismo-, la autenticidad permitiría la articulación en el sentido de interpretación y comprensión de la realidad social ${ }^{36}$.

sobre otro en razón de considerar una preferencia de segundo orden según la cual, por ejemplo, el interés por lo desconocido me lleva a relegar el sol y la playa en favor de conocer nuevos paisajes.

Parecería, aunque no queda del todo claro, que la condición A) de la autenticidad serviría únicamente para sopesar deseos o motivaciones que no encierren valoraciones morales. De ser así sólo la condición B) permitiría conferír a nucstras preferencias un horizonte valorativo, dándoles el carácter de evaluaciones en sentido fuerte, en el marco de una concepción del bien. A pesar de que Taylor especifica que, según se verá más adelante, las dos condiciones son igualmente importantes en la definición de autonomía, sabemos que para él las elecciones del simple sopesador no son las que determinan su identidad. Las que participan en su identidad son las elecciones del evaluador fuerte, y éstas sólo pueden realizarse en el marco de la condición B). De modo que podemos pensar que para Taylor la autonomia personal consiste en la capacidad para llevar a cabo elecciones morales exclusivamente.

34 Véase Taylor (1992, capítulos I y II).

3 Véase Kymlicka (1995: 239).

3t. Véase Thiebaut, introducción a La ética de la autenticidad, de Charles Taylor, 1994. 


\subsection{Dos versiones de la tesis contextualista de la autonomia}

Según Taylor, el riesgo de subjetivismo acompaña a posturas relativistas que insisten en exaltar el componente de originalidad que encierra la autenticidad. Para reformular la idea de autenticidad y dotarla de objetividad introduce la condición B) -confrontación de la elección con los horizontes de sentido dados- como condición necesaria para la autenticidad, no bastando con la verificación de la condición A). Para explicar la importancia de los horizontes de sentido Taylor recurre al ejemplo de la orientación sexual. Argumenta que en el intento por justificar la elección sexual de quienes se inclinan por opciones homosexuales en lugar de por las más ampliamente aceptadas relaciones heterosexuales, se hace hincapié en el valor de la elección misma, en el valor de la diferencia, la diversidad, la pluralidad de opciones, equiparando tales opciones en cuanto a su valor, ya que éste estaría dado por el hecho de ser producto de la libre elección individual; el poder llevar a cabo la elección estaría confiriendo valor a la misma, independientemente de su contenido material (1994: 73). Taylor critica esta idea e insiste en que debe otorgarse valor no a la elección en sí, a la acción de optar o escoger una orientación u otra, sino a las opciones por lo que ellas entrañan, a una vida homosexual o a una vida heterosexual por lo que de valioso tengan estas experiencias respectivamente, de modo que no cualquier elección sería correcta o valiosa.

Michael Sandel, que ha sostenido posturas aún más fuertemente contextualistas que las de Taylor, hace un análisis similar respecto de cómo deben valorarse las elecciones individuales. En un trabajo aparecido en el año 1989 realiza un resumen de cómo el derecho a la privacidad ha sido revisado por la Corte Suprema de los Estados Unidos en el sentido de defenderlo sobre la base de una visión sofisticada y voluntarista del mismo. Analiza para ello diversos casos en que se sometió a consideración la penalización de la distribución y utilización de anticonceptivos ${ }^{37}$ así como los conocidos casos de Roe vs. Wade ${ }^{38}$ sobre el aborto y de Bowers vs. Hardwick sobre la penalización de la homosexualidad ${ }^{39}$. Sostiene Sandel que de llevarse a cabo la defensa de una práctica privada como es la relativa a la opción sexual de cada uno - la homosexualidad en el caso de la citada sentencia - tal defensa debe basarse en el valor sustantivo otorgado a la práctica y no en el concepto voluntarista del derecho a la privacidad, que la entiende sobre todo como capacidad para hacer uso de la autonomía personal. Según Sandel, omitir considerar las cuestiones morales que se plantean en casos como los de las sentencias antes mencionadas, defendiendo las acciones o prácticas en cuestión -utilización de

"Poe vs. Ullman, 367 U.S. 497 (1961); Griswold vs. Connecticut, 381 U.S. 479 (1965); Eisenstadt vs. Baird, 405 U.S. 438 (1972); véase Sandel (1989).

IN 410 U.S. 113 (1973); véase Sandel (1989).

478 U.S. 1986 (1986); véase Sandel (1989). 
anticonceptivos, aborto, homosexualidad - con base en el derecho a la libertad de cada uno para decidir sobre cuestiones que afectan a su propio plan de vida, estaría en realidad socavando el valor de dichas opciones. La mera tolerancia respecto de ciertas prácticas deja abierta la cuestión sobre la calificación moral de dichas prácticas, o aún peor, en algunos casos el no pronunciarse al respecto pondría en evidencia un velado juicio negativo al respecto ${ }^{40}$. En la interpretación de Carlos Thiebaut los derechos, según la postura de Sandel, deben encontrar su fundamento y la razón para su protección en «la bondad de su contenido", en la aprobación - por parte de la comunidad- del fin que persiguen y no en una idea aséptica como es la de la universalidad de los derechos.

Así, para defender por ejemplo la homosexualidad debería argumentarse a favor de las bondades de la vida homosexual incorporándola a nuestro horizonte de significado, de modo que la opción cobrara sentido, adquiriera relevancia moral y pudiera convertirse en una opción valiosa, una opción reconocida como valiosa. Las distintas opciones pujarian por obtener reconocimiento en el marco de significación que otorgan los horizontes de sentido, y sólo a la luz de dicho reconocimiento podrían ser consideradas opciones valiosas o disvaliosas, según el caso. Pero de cualquier modo su valor dependerá de ese reconocimiento. Por ejemplo, en el caso de la homosexualidad, la condena a que se establezcan normas que la discriminen no debería llevarse a cabo invocando el principio de autonomía de la persona o de tolerancia, sino realizando una analogía entre la homosexualidad y la heterosexualidad en el sentido de enfatizar que ambas prácticas pueden conducir a la realización de objetivos valiosos — «promoción de un estilo de vida», «armonía en el vivir», «lealtad bilateral», según lo señalado respecto del matrimonio por la Corte de los Estados Unidos en Griswold vs. Connecticut ${ }^{41}$.

Raz se acerca a este punto cuando analiza cómo se configuran las opciones entre las que la persona autónoma puede escoger, que como vimos resultan de especial relevancia en su concepción de la autonomía. Según el autor, la forma que adoptan las opciones y el valor que revisten depende directamente del entorno en que surgen. En primer lugar debe existir un contexto favorable al desarrollo de la autonomía personal para que ésta se manifieste en una pluralidad de opciones «adecuadas». Raz utiliza, entre otros, el ejemplo de la elección de la persona con quien uno desea contraer matrimonio. En el pasado la no elección de la pareja o la imposición del matrimonio con determinada persona por parte de los padres era la forma habitual en que se formaban nuevas parejas. Hoy mayores posibilidades se han abierto para que las personas

4 Sandel hace notar cómo cn Bowers vs. Hardwick la defensa del derecho a la privacidad en la que se basan quienes defienden la no interferencia en las prácticas homosexuales consensuadas, lejos de promover una actitud de respeto hacia la homosexualidad concede una precaria aprobación (1989:537).

"Véase Sandel (1989:527). 
pucdan elcgir con quién desean -si desean- contraer matrimonio (1988: 394). Lo que en un momento no se consideraba una intromisión indebida en el desarrollo de un plan de vida viene a considerarse como tal en un momento posterior. Esta nueva posibilidad es fruto de una evolución en la que la autonomía es tenida en cuenta de manera preponderante en nuevos ámbitos, siendo reforzada y reconocida como condición fundamental para la plena realización del plan de vida personal.

La postura de Raz defiende la distinción ya señalada entre la autonomía en sentido kantiano y el moderno concepto de autonomía. En las sociedades modernas, tal como las conocemos en el mundo occidental, conviven ambas instancias, de modo que la autonomía es concebida en un doble sentido. Por un lado, la autonomía como capacidad, que una vez adquirida por el agente es considerada un valor en sí mismo, una capacidad universal cuyo ejercicio no está comprometido con una determinada opción valiosa (1988: 395). Por otro lado, existe un aspecto de la autonomía que está directamente relacionado con el contexto o el entorno en el que es ejercida y que la hace dependiente de las opciones que ese entorno promueve o favorece.

A pesar de las semejanzas que se pueden trazar entre la idea comunitarista de autenticidad que se ha descrito y la teoría de la autonomía de Raz, los presupuestos en uno y otro caso son diversos. Ambas concepciones toman la autonomía en sentido kantiano y la reubican en el contexto social, que es el que sirve de marco para que la persona autónoma desarrolle su plan de vida. Los planes de vida son concebidos en función de las opciones que la sociedad ofrece al individuo, y es por ello que la capacidad para autodeterminarse se acota o se acomoda a las posibilidades del medio, sin por ello despreciar la capacidad del individuo para a su vez reelaborar a partir de la iniciativa personal aquello que viene dado por el contexto. Esta aproximación a la idea de autonomía contextuada es abordada de muy distinto modo según la concepción de persona - self o human agency - que se adopte y según las premisas que se asuman en el plano ontológico.

Taylor reconoce a la persona o self por su capacidad para llevar adelante sus elecciones, sostener su propio punto de vista, defender unos determinados valores y desarrollar planes de vida. Hasta aquí la propuesta no se apartaría de la concepción de persona autónoma que también el liberalismo -en sus diversas variantes- sostiene. Sin embargo, a la persona así caracterizada Taylor la llama respondent en el sentido de persona a la que podemos dirigirnos con la expectativa de obtener una respuesta original, vale decir que el agente no se expresa simplemente dando cuenta de la representación o conciencia de la realidad, sino que le confiere un significado propio (1985: 99). Taylor quiere oponerse con esta definición al utilitarismo en su concepción de la persona como agente capaz de evaluar sus preferencias y calcular cuál es la elección que lo llevará a obtener el resultado deseado. En la concepción de Taylor en cambio las personas no se distinguen por su capacidad para la planificación 
«estratégica», sino por el poder para evaluar la calidad de ciertos fines. Desplaza el centro de atención de la capacidad de elección y planificación a la capacidad para tomar posición respecto de ciertas pautas implícitas en los fínes de las personas. Dichos fines cobran significado sólo en su contexto de referencia - «... against the background of significance» (1985: 108). Es en contraste con el contexto de significación que nuestras evaluaciones y elecciones cobran sentido. El individuo escoge sus fines después de una búsqueda guiada por principios morales objetivos dados, no elegidos autónomamente. Pensar en un espacio neutral en el que el agente pueda realizar sus elecciones sustrayéndose de su espacio cultural es para Taylor una ilusión (1985: 112).

Detrás de la idea de persona que sustenta el comunitarismo hay siempre una idea del bien capaz de dar respuesta a todas las preguntas que el agente autónomo se plantee. De este modo, la autodeterminación topa no ya con opciones socialmente moldeadas, sino con respuestas definidas - determinadas- que ayudan al sujeto en su tarea de «descubridor» de su propia identidad. Para Taylor, cada vez que el self se determina autónomamente optando por las alternativas que dan forma a lo que será su plan de vida, lo que hace en realidad no es construir su identidad ex novo, sino que descubre su identidad a través de las fuentes morales que el entorno pone ante sí. Esta tarea incumbe al individuo autónomo y no puede ser coaccionado o manipulado en el logro de la autorrealización en el sentido en que antes fue definida - como satisfacción de aquellas capacidades relevantes para desarrollar el plan de vida deseado.

La diferencia entre la concepción de Raz y la que sostienen comunitaristas como Taylor o Sandel está en que para estos últimos las opciones no son más que artilugios formales que en todos los casos convergen en una teoría del bien que las define. Los horizontes de sentido no son orientativos para la elección entre diversas opciones, sino que son constitutivos, y en tal sentido vinculan de tal modo a la persona con su entorno que sea cual sea la opción que desarrolle el agente, lo que haga no será otra cosa más que desarrollar lo que ineludiblemente estaba contenido en los horizontes de sentido.

Para Raz, en cambio, las opciones valiosas son plurales en sus contenidos, es decir, que atienden a diversas concepciones del bien. Esto significa quc entre las opciones que se presentan a la persona hay diferentes formas de vida, todas las cuales atienden a valores incompatibles entre sí. Si bien Raz señala que su concepción de la autonomía adhiere a un pluralismo de valores débil o moderado, esto no obsta a una teoría según la cual el conflicto entre las diversas opciones sigue siendo una condición para la realización de la autonomía (1986: 398).

Esta condición no está presente en la idea de autonomía que sustenta el comunitarismo. Taylor pretende demostrar que la subjetividad que entrañan posturas que centran su atención exclusivamente en la persona autónoma debe complementarse con la objetividad que aportan los horizontes de sentido - a 
pesar de que la idea de horizonte de sentido es compleja y parece involucrar elementos muy diversos, no todos ellos portadores de objetividad.

Scgún Taylor, ambas condiciones - A y B - son igualmente importantes y no debe anteponerse una a la otra. El problema radica precisamente no en que Taylor añada a la autonomía un valor instrumental, sino en que anula su valor intrínseco. Como dice Young (1986: 30), la autonomía puede ser tambiên instrumental, pero su valor es en primer lugar, ante todo, intrínseco. Taylor, al establecer que tanto la condición $\mathrm{A}$ como la $\mathrm{B}$ son indispensables para la autonomía, no otorga prioridad al valor intrínseco sobre el valor instrumental, sino que los ubica en pic de igualdad.

\section{CONCLUSIONES}

El problema que presenta la definición de autenticidad de Taylor resulta de sostener que la autonomía es a la vez capacidad para la autocreación - y en consecuencia es voluntad independiente en el sentido en que la concebía Kant- y condición para la autodefinición a partir de contextos de significado fijos e ineludibles. $O$ bien prevalece el contexto de determinación y en consecuencia las elecciones que efectuamos son elecciones triviales, o bien las elecciones son significativas y en consecuencia la pertenencia a una comunidad no puede ser constitutiva de la identidad personal. El individuo cuya identidad se encuentra constitutivamente ligada a la comunidad a la que pertenece es un individuo cuya autonomía no puede ya ser descrita con los elementos de la autonomía kantiana - racionalidad e independencia- ni tampoco con los elementos de la condición A) de la autenticidad como la postula Taylor. Para que pueda predicarse la existencia de autonomía en las elecciones del agente no puede éste ver interferido su proceso de elección, a través del cual se define también su identidad por un marco único ineludible y preexistente. Si se sostiene, como hace Taylor, que la identidad individual se disuelve en el holismo comunitario, la autonomía queda relegada no ya a opciones previamente trazadas por el contexto - tesis de Raz-, sino a elecciones previamente determinadas por los horizontes de sentido. Esto último equivale a negar la posibilidad de autonomía personal.

La de Taylor resulta una idea compleja del individuo, un self o agente que no sólo se vale de la razón - de su independencia racional-, sino que también se define a sí mismo a través de un entorno - social, cultural, histórico, de tradiciones y valores - que es exterior al individuo. En términos kantianos esto equivaldría a la descripción de un individuo heterónomo, es decir, de un individuo que condiciona su obrar a agentes externos. El moderno concepto de autonomía reconoce la influencia decisiva de la socicdad en la configuración de las opciones, y afirma que a través de tal configuración el contexto condiciona la elección individual. La tesis comunitarista da todavia un paso más en las concesiones a la influencia del contexto, sosteniendo que la comunidad es 
fuente constitutiva de la identidad personal. Si el entorno ejerce una influencia tal sobre la persona que ésta ya no puede dirigir sus acciones sobre la base de sus propias motivaciones o deseos, cabe preguntarse si la mera adhesión a unos principios preexistentes - sociales o comunitarios - es suficiente para considerar a un individuo como autónomo. Cuándo las influencias del entorno pasan a ejercer una presión tal sobre el individuo que anulan su capacidad de reflexión y elección, ésta es difícil de medir. Conforme a la definición de autonomía que la caracteriza como la capacidad para determinar racionalmente el propio plan de vida, parece claro que para preservar dicha capacidad ningún factor externo o interno puede coaccionar a la persona de modo tal que quede aquélla en una encrucijada determinista. Si lo hace, habrá cedido su autonomía ${ }^{42}$.

En palabras de Thiebaut es el «holismo ontológico» el que no permite al sujeto, tal como lo describen los comunitaristas, tener perspectiva respecto de las normas y valores para poder a su vez asumir una actitud crítica (1992: 159). Esta concepción holista descansa a su vez en la presunción de homogeneidad que afectaría tanto a la sociedad como a los valores compartidos cuando la comunidad se percibe a sí misma compartiendo una misma idea del bien. El resultado de ello sería una «noción homogénea y no compleja de comunidad» (1992; 161) que niega la diversidad, la pluralidad y la diferencia reconocida precisamente en el valor de la autonomía personal. Porque creen en el falso postulado de la homogeneidad de valores entre los individuos en sociedad, pueden los comunitaristas hacer desacansar la autonomía en condiciones externas, en el contexto de determinación, sin que aquélla contradiga la autodeterminación individual, ya que presuponen valores homogéneos universalmente aceptados por los miembros de la comunidad. Sin embargo, la homogeneidad moral así entendida no es ni mucho menos un presupuesto de la filosofia práctica y su fundamentación requeriría por parte del comunitarismo mayores esfuerzos argumentativos.

\section{BIBLIOGRAFÍA}

Aluson, Henry E. (1990): Kant's theory of freedom, Cambridge University Press. - (1996): Idealism and freedom. Essays on Kant's theoretical and practical philosophy, Cambridge University Press.

BAYLES, Michael D. (1978): Principles of Legislation. The uses of political authority, Wayne State University Press, Detroit.

Bayon, Juan Carlos (1991): La normatividad del derecho: deber juridico y razones para la acción, Centro de Estudios Constitucionales, Madrid.

BEN, Stanley I. (1988): A Theon of Freedom, Cambridge University Press.

Berlin, Isaiah (1986): Four Essays on Liberty, Oxford University Press.

\footnotetext{
40bre obstáculos externos e internos a la autonomia personal ver Young 1986: 33-62.
} 
Christman, John (cd.) (1989): The inner citadel. Essays on individual autonomy, Oxford University Press.

Colomer Martin-Calero, José Luis (1995): La teoria de la justicia de Immanuel Kant, Centro de Estudios Constitucionales, Madrid.

Dworkin, Gerald (1992): "Is more choice better than less?", Midwest Studies in Philosophy, vol. 7, pp. 47-61.

Fallon, Richard H. Jr. (1994): "Two Senses of Autonomy", Stanford Law Review, vol. 46, núm. 4, pp. 875-905.

Frankfurt, Harry G. (1971): «Freedom of the will and the concept of a person», The Joumal of Philosophy, vol. LXVIII, núm. I, pp. 5-20.

Hurley, Susan L. (1989): Natural Reasons. Personality and polity, Oxford University Press.

KymlickA, Will (1989): Liberalism, Community and Culture, Clarendon Press, Oxford.

- (1995): Filosofia política contentporánea, Ariel, Barcelona.

LAporra, Francisco J. (1983): "Sobre el uso del término "libertad" en el lenguaje política», Sistema, núm. 52 , pp. 23-43.

- (1995); «mperio de la ley. Reflexiones sobre un punto de partida de Elías Díaz», Doxa, núm. 15-16, vol. 1, pp. 133-146.

MACINTYRE, Alasdair (1985): After Virtue. A study in moral theory, Duckworth, London.

- (1987): Tras la virtud, versión castellana de Amelia Valcárcel, Editorial Crítica, Barcelona.

MatTeini, Maria (1995): MacIntyre e la rifondazione delletica. La crisi delle ideologie $e$ della morale e il recupero del finalismo etico come «bene comune», Città Nuova, Roma.

RAZ, Joseph (1986): The Morality of Freedom, Clarendon Press, Oxford.

- (1989): «Liberalism, Skepticism and Democracy», Iowa Law Review, 761.

- (1991): Razón práctica y nomas, traducción de Juan Ruiz Manero, Centro de Estudios Constitucionales, Madrid. Versión original Practical Reason and Norms, Princeton University Press, 1990 (2, ed.).

- (1995): «Rights and Politics», Indiana Law Review, vol. 71, pp. $27-44$.

SANDEL, Michael (1982): Liberalism and the limits of justice, Cambridge University Press, Cambridge.

- (1989): «Moral argument and liberal toleration: abortion and homosexuality", California Law Review, vol. 77, núm. 3, pp. 521-538.

TAYLor, Charles (1976): «Responsibility for self», en The identities of persons, Amélie Oksenberg Rorty (editora), University of California Press, California.

- (1985): Human Agency and Language. Philosophical Papers 1, Cambridge University Press.

- (1989a): Sources of the Self. The making of the modem identity, Cambridge University Press; versión española de Ana Lizón, Fuentes del yo. La construcción de la identidad moderna, 1996, Paidós, Barcelona.

- (1989b): «Cross-Purposes: The Liberal-Communitarian Debate», en Liberalism and the Moral Life, Nancy L. Rosenblum (ed.), Harvard University Press, Cambridge, Massachussetts.

- (1990): «El atomismo», en Derecho y moral, J. Betegón y J. R. de Páramo (cds.), Barcelona, Aricl; v. o. «Atomism», en Philosophy and the Human Sciences. Philosophical Papers 2, Cambridge University Press. 
- (1992): Philosophy and the Fuman Science. Philosophical papers 2, Canadá, Cambridge University Press.

- (1994): La ética de la autenticidad, Paidós, Barcelona; v. o. The malaise of modemity, 1991, House of Anansi Press Limited.

Thebaut, Carlos (1992): Los limites de la comunidad, Centro de Estudios Constitucionales, Madrid.

Tuck, Richard (1994): "Rights and pluralism», en Philosophy in an age of pluralism, James Tully (ed.), Cambridge University Press.

Tuldy, James (1994): Philosophy in an age of pluralism. The philosophy of Charles Taylor in question, Cambridge University Press.

WALDRON, Jeremy (1989): «Autonomy and perfectionism in Raz's Morality of Freedom», Southem Califomia Law Review, vol. 62, pp. 1097-1152.

Wrighr, Georg Henrik von (1963); Norm and Action: a logical enquiry, Routledge \& Kegan Paul, London.

Young, Robert (1986): Personal Autonomy. Beyond Negative and Positive Liberty, Croom Helm, London. 